\title{
Wave or Trend
}

\section{Female Candidates in Pennsylvania Elections in the Trump Era}

JOSHUA J. WEIKERT

Immaculata University

The 2018 elections saw a record number of women running for elected office in the United States and in Pennsylvania, but whether this represents a temporary wave or a lasting trend is not clear. Using a combination of survey data; interviews of new candidates, elected officeholders, and party officials; and election data, this study examines the gender equality gains of 2018 in Pennsylvania's legislature in historical and political context. The data provide evidence that formal recruitment of female candidates was common (but not universal), that the number of women running for and winning office increased by historic (and not just significant) levels, and that a persistent and consistent motivation was discernible in large portions of the candidate body. Survey measures of female candidate persistence-whether they plan to run again or recruit new candidates-also indicate that women intend to remain similarly active after the 2018 election cycle has come and gone.

41 n 1992, women's time may have come. . . It seems clear that 1992 has been a watershed of sorts and that the 1990s may well be the Decade of the Woman." Thus wrote Delli Carpini and Williams in 1993 (32, 36), citing a combination of factors such as the end of the Cold War and renewed salience for domestic issues in American politics, a greater 
number of female candidates, new pro-women advocacy groups and PACs, recent Supreme Court decisions regarding abortion, and (most importantly, in the authors' estimation) the Anita Hill testimony at the Clarence Thomas hearings before the Senate Judiciary Committee. While 1992 did witness an increase in the number of women running for office, the results were less than encouraging in both the short and long term. Most 1992 female candidacies were unsuccessful, and the increased number of women running for office reverted rapidly to its earlier mean (Center for American Women in Politics 2019). These results show that the optimism of 1992 was, perhaps, misplaced, and that 1992 represented a wave, not a trend. In the wake of the 2018 elections, we find ourselves again witnessing what appears to be a "Year of the Woman." This article seeks to test, in a limited fashion, whether 2018 is simply a rerun of the wave of 1992, rising and cresting before its ultimate recession, or the beginning of a new trend toward greater representation by virtue of a shift in gender-relevant incentives and political conditions.

It is a basic, unassailable, empirical fact that women are underrepresented in American representative political bodies. The general belief in representational equality increasing as we get closer to the local level ("municipal advantage") is itself sometimes described as being more intellectually fashionable than empirically demonstrable, with findings that female representation in government hovers at about 25\%, regardless of level (Tolley 2011, 573). Indeed, at present the municipal advantage "trend" actually reverses at the local level. Of the 1,365 cities and towns in the United States with a population greater than 30,000, only $21.8 \%$ have female mayors (Center for American Women in Politics 2019). The Pennsylvania General Assembly is below average for women in state legislatures as a whole. What is, perhaps, most remarkable is that this below-average performance represents a substantial improvement over recent history: a record number of women sought office in the 2018 election cycle (Caygle 2018), and the 2018 elections added substantial numbers of women to the Pennsylvania House (a net of 9 gains, from 42 to 51 ) and nearly doubled the number of women in the Senate (from 7 to 12).

This study examines whether this is a unique event brought about by the current political climate or whether it represents a fundamental (and, potentially, lasting) change in electoral politics in the Commonwealth. Gender equality in the General Assembly is not exactly the main focus here, though it represents a starting point. The questions addressed here are whether the gains that we have seen (or are likely to see) are sustainable, and whether these women running for office represent a statistical anomaly or the vanguard of a new more-gender-equal legislative bloc. In order to predict sustainable progress toward gender parity in representative bodies, we need to see more than 
just a historical-contextual increase in the percentage of women running for or are in office in one year or term. After all, as 1992 showed, political "Year[s] of the Woman" have been touted in the past only to be followed by a reversal or subsequent slowing of representational progress. Is 2018 different, and if so, how is it different? There are three conditions that would be necessary (if not necessarily sufficient) to justify the belief that recent gains in representation are likely to be persistent:

- Substantively significant recruitment of female candidates by party leaders ("recruitment," as defined in this article, refers to an approach by a party official or activist toward an individual to solicit candidacy, per Norris 2006) (see Brown, this issue)

- An increase in the number of women who run for office (whether recruited or self-selected)

- An underlying and persistent motivating factor that incentivizes female candidacy.

Why these three conditions? The first two speak to the necessities of getting to the starting gate and running the race as general preconditions of winning seats and shifting the gender percentages in these bodies. If women are not being recruited to run, or if political, social, and personal conditions are not conducive to women deciding to seek office, then gains are not possible. A measurable and robust level of active, formal recruitment by a party or parties could signal an institutional commitment to greater gender balance, a perception that women are more "electable" and that such candidacies are more likely to be successful in the political climate, or both. At the same time, an increase in the number of women who are receptive to recruitment or who bypass it completely and decide to run without recruitment is a signal of greater overall female interest in candidacy and prospective erosion of the socalled "ambition gap." The third condition speaks to the question of whether gains are sustainable, not merely possible: the circumstances that create a wave are not the same as an environmental shift that will reliably increase female candidacy or success, and it is the latter that is required if the wave is to become a trend. Is 2018 the new 1992? As in 1992, more women sought office, but they experienced greater success and the motivation for their candidacies is, arguably, less tied to the specific contemporary events of recent years and more closely relatable to a persistent and future-oriented policy "threat." The survey data generated by this study (as well as the electoral outcomes of 2018) suggest that, in fact, this may be the beginning of a trend rather than the end of a wave. 


\section{Background: Getting to the Starting Gate}

This is about the decision to run for office. Whether a shift toward genderequal representation is a wave or a trend, the first stage is the same: an increase in the number of women seeking office. No one is elected who does not throw their hat into the ring-and historically comparatively few decide to throw their hat into the ring who are not recruited (Norris 1997). This is especially true for women, who historically are less likely to consider themselves as prospective candidates (Lawless and Fox 2008). The "ambition gap" (itself a combination of a lack of recruitment, a lack of interest in campaigning, and self-perceived lack of electoral viability) increases the salience of the factors that go into candidate recruitment. Recruitment is thus, in turn, central to our understanding of gender representation, at least in the absence of an external or contextual factor that may encourage more women to proactively seek public office. Who gets to the starting gate?

Candidate recruitment is not an area that has been ignored or even necessarily neglected by our discipline: it only seems so in comparison to the avalanche of studies in related areas within the campaigns-and-elections subfield. There is valuable work illustrating models of candidate recruitment, the role of parties and partisanship in state/local and federal candidate recruitment, and prospective candidate selection criteria. With this context established, the rationale for the survey methodology employed becomes more intuitive: assessing the sustainability of the present level of political interest and activity among female office-seekers in Pennsylvania requires more than the "who" answers provided by the election data. It also benefits substantially from an assessment of why those women reached the starting gate and whether they intend to assist others in reaching it and run more races themselves. The responses of the candidates offer unique insights into the process and environment described below.

\section{The Party Decides}

The general model of candidate recruitment (see Norris 1997 for a detailed description) maps out a series of narrowing gates, beginning with formal legal, electoral, and party barriers to entry that limit the pool of prospective candidates. Those who pass through this initial screening may then be subjected to a recruitment process in which both formal and informal rules and procedures further limit the supply of aspirants to office and which incorporates the demands of partisan gatekeepers. The interaction between gatekeepers and aspirants leads to an outcome in which either actor may play a veto role, though the existing literature places significant focus on the decision-making 
power of the partisan gatekeeper in addition to that of the aspirant (Norris and Lovenduski 1993; Kunovich and Paxton 2005; Cheng and Tavits 2011; see Sweet-Cushman 2018 for a Pennsylvania sample). Admittedly, the partisan "path to power" is much more tightly guarded in European and Canadian politics, whereas in the United States virtually any individual can choose to run for public office, recruited or not. Despite this relative lack of party power to formally block unrecruited candidates from the ballot in the United States, there is evidence to suggest that the affirmative element of recruitment-that it acts as a stimulus to candidacy among potential candidates-is a feature shared in the American system. Ambition (or lack thereof) is a commonly described feature of the representational gender gap, but formal recruitment provides a bridge that has the potential to close that gap (Preece, Stoddard, and Fisher 2016).

The specific functioning of this general model is affected by structural factors, most notably the organizational model of the party in question (which is, naturally, also a function of the electoral system in question). Recent studies note that even in relatively open electoral systems, a cartel model predominates. Although formal barriers are set relatively low, the recruitment networks operated by partisan cartels-whether formal or informal-are largely closed (Rallings et al. 2010; Aldrich 2000). Data suggest that most candidates are selected and approached to stand for office, rather than being evaluated following a proactive application for consideration by the prospective candidate in question (Rallings et al. 2010, 370). This cartel model-featuring a professionalized political class of gatekeepers-results in candidates with a generally higher level of quality than those in systems with more "wildcat" or insurgent candidacies, but at the expense of a more-insular and less-diverse body of candidates (Krouwel 2006, 250).

Partisanship and party competition are demonstrably related to the level of interest in candidate recruitment, if not the fundamental results (which candidates end up on the ballot). This has been disputed in terms of recruitment for local offices, with one theory positing that local politics is insulated from broader questions of partisan conflict (Williams and Adrian 1959), though the theory has not been consistently supported. However, at higher echelons of party office-seeking (national and prominent subnational offices such as governors), parties are intimately involved in the candidate recruitment process, especially when competition is pronounced. The motivation and rationale is perfectly summarized in Sanbonmatsu:

Party scholars have long theorized that party competition is related to party organizational strength (e.g., Beck 1974; Crotty 1968; Key 1949; Patterson and Caldeira 1984; Schlesinger 1985). Whether the parties 
successfully recruit candidates helps determine whether voters are offered a choice between the two major parties on election day (e.g. Downs 1957). Because capturing office is arguably the main goal of the party (Downs 1957; Schlesinger 1975), fielding candidates is a necessary condition for parties to win elections. As Seligman $(1961,77)$ summarizes: "The recruitment of political candidates is a basic function of political parties: a party that cannot attract and then nominate candidates surrenders its elemental opportunity for power." $(2006,235)$

Sanbonmatsu found little evidence of an explicit gender bias, but did note that party recruiters and gatekeepers tended to be men, which creates a like-type and in-network bias which almost certainly decreases the probability of recruiting women. Contrary to "insulation" doctrine, we have evidence in the literature (as well as in this study) that local-level party organizations engage in recruiting at about the same intensity level as state- and national-level party organizations (Kazee and Thornbury 1990, 61). At a minimum, then, we should expect that any increase in female representation (itself being a product of increased representation in candidacy) to be at least somewhat reliant on an increase in female candidate recruitment (and, very probably, female recruiters).

\section{Gender as a Variable}

There is a heavy emphasis in the political science literature on the "gendered" nature of political candidate recruitment, examining whether screening based on gender is limiting diversity in politics (Norris and Lovenduski 1993). Not all candidates are necessarily recruited, nor are all recruits necessarily candidates. In the absence of recruitment, though, gender-specific aversion to electoral competition (the aforementioned ambition gap) and the "care penalty" (sociological bias in the assigning of child and elder care duties which disproportionately overburdens women) are difficult to overcome, and recruitment increases by several times the probability of a woman to run for office (Fox and Lawless 2010; Kanthak and Woon 2015). Thus, gender as an independent variable influencing the probability of recruitment is an important consideration in determining gender equality in representative bodies.

There is consistent evidence that gender is a factor in recruitment both at the state and national levels (Thomas 1994), and that the male advantage in recruitment exists whether it is the party or a nonpolitical actor doing the recruiting (Lawless and Fox 2008, 8). This lack of distinction between federal and state recruitment mirrors the overall lack of representation noted earlier at the federal and state levels and municipal offices. Moreover, we 
see that this trend exists in both parties (Freeman 2000), though it should be noted that recent history indicates an increasing asymmetry (Center for American Women in Politics 2019). The Republican Party has become more male-dominated in numbers of nominees and elected officials even as the Democratic Party becomes more representative (though still unequal), which reflects a growing gender gap between the parties more generally (Rubin 2018). There is also evidence that partisanship plays a role in the success or failure of female recruitment, with Democratic women being more responsive, on average, than Republican women (Sanbonmatsu 2002; Preece, Stoddard, and Fisher 2016). The gender of the recruiter is also positively correlated with increases in the number of female candidates. Women are more likely to recruit women (Cheng and Tavits 2011; Crowder-Meyer 2013) and are more likely to run when being recruited by women (Sanbonmatsu 2006, 235).

Research also indicates that even when women are recruited for candidacy, it is more likely to be for a run as a "sacrificial lamb" in a long-shot district than as a competitive candidate, and that female incumbents are less "safe" than male incumbents (Bernstein 1986; Carroll 1994; Thomas and Bodet 2013). This kind of symbolic recruitment or nomination is counterproductive. Not only does it not realistically increase the likelihood of gender equality in the legislatures in question, it creates an impression that female candidates are an electoral liability and not productive targets for candidate recruitment. This almost certainly has downstream effects when parties allocate electoral resources (funding, volunteers, staff, and so on). However, parties do not have exclusive control over the machinery of candidacy. Women can proactively decide to run even if not recruited, and parties may also encounter shifts in public sentiment that incentivize the recruitment of female candidates.

Ultimately, gendered recruitment is a major factor in lack of representation. The probability of deciding to run for office (controlling for other factors like self-perceived electability, qualifications, time availability, and interest) nearly triples for a woman who is recruited to run for office compared to a woman who is not (Fox and Lawless 2010, 321). Recruitment is not so much a nudge as a shove, and it is of sufficient magnitude to overcome much of the reluctance and "election aversion" demonstrated in the literature.

\section{"The Trump Effect"}

The conditions noted previously and their impact on the supply of female candidates (how many women want to run, how many women are recruited to run?) and the demand for female candidates (are voters more likely to vote for women?) are unlikely to change suddenly in the course of one or two election 
cycles. What if a political proximate cause was sufficiently jarring to the system so that a larger shift was caused that provoked a new equilibrium, rather than just a shock followed by a reversion to the mean? This brings us to the election in 2016 of Donald Trump. By any standard this was a political shock.

What remains to be seen is what effect it ultimately has on the universe of candidates and electoral victors. After all, the treatment of Anita Hill prompted an increase in the number of women seeking office in 1992, but the net result (in its own era and in comparison to the years since) shows that it did not set off a larger trend of women running for or winning public office (Delli Carpini and Williams 1993; Center for American Women in Politics 2019). Indeed, in Pennsylvania the 1992 "Year of the Woman" elections yielded an increase in the number of women in the House of Representatives of only 3 , from 21 to 24 . Prior to the 2018 elections, that number had increased to 41 in a generally steady rise with no particular external causes (Pennsylvania Center for Women and Politics 2019).

Would there be a "Trump Effect"? This was the question pursued by Lawless and Fox (2017) in their report of the same name. The overall argument for gendered effects from the election of Donald Trump is outlined by Lawless and Fox early on in their report (2017, 1-2): the policy agenda proposed during the 2016 campaign, sexist statements by Trump the candidate, and President Trump's personal history with women (which includes multiple accusations of sexual harassment or assault) combine to motivate political engagement among women who would otherwise be unlikely to participate. It is not necessarily the case that it is a gender exclusive effect-Trump undoubtedly provoked reactions from those of both genders in both parties-but the survey data in Lawless and Fox show that women had a stronger reaction in terms of both interest and activity. They found that respondents to their survey were much more likely to take political action but were only slightly more likely to consider running for office. Lawless and Fox were cautiously pessimistic on the question of a "Trump Effect" resulting in more female candidates: "On balance, the evidence suggests that very few women will emerge from the overall pool of potential candidates" $(2017,12)$.

\section{Research Questions and Methodology}

Thus, we return to the three conditions posited earlier. When we look at the 2018 election, do we see:

- Substantively significant recruitment of female candidates by party leaders? 
- An increase in the number of women who decide to run for office (whether recruited or self-selected)?

- An underlying and persistent motivating factor that incentivizes female candidacy?

Lawless and Fox (2017) apparently thought that we were unlikely to see these three things. However, such questions can now be answered empirically, and those answers can inform our assessment of whether a trend toward greater participation by women in the electoral process as candidates exists and is likely to continue and accelerate. Evaluating these questions can (additionally and conveniently) now be done in light of the results of the 2018 general election. A high rate of success among the women who ran for office in 2018 has the potential to activate the advantages of incumbency, protecting both the absolute gains made in gender equity in elected offices in the state as well as preserving the trend of greater female participation as candidates. Even absent that effect, though, there may still be reason to believe that a much more gender-equitable political recruiting environment will persist. If female candidates report that they are likely to run in future cycles regardless of outcome, that they plan to recruit other women to run, and if party leaders indicate a greater desire for female candidates, then we may reasonably conclude that this is more a trend than an anomaly.

Discerning motivation is a substantial challenge in social science research. Since the present and future motivations of the units of analysis in this case (the candidates themselves) are central to addressing the research questions posed earlier, a survey of those candidates that allows for the direct and indirect assessment of those motivations is indicated. Clearly, any evaluation of potential incumbency advantage accrual also requires that we consider the election record as well. As a result, this research uses three bodies of data: pre-election surveys of female candidates, post-election follow-up with a portion of those survey respondents, and the results of the 2018 Pennsylvania elections.

Election data were retrieved from the Pennsylvania Department of State Election Results website (https://electionreturns.pa.gov/). Survey data were generated by first compiling a list of all candidates for the Pennsylvania General Assembly, both the House of Representatives and the Senate. That list was then sorted by gender of the candidate and a list of female candidates was created. Finally, the list was filtered to remove incumbent candidates who were running unopposed in the general election under the conclusion that their reported motivations could be qualitatively skewed by their lack of opposition and they have a fairly obvious answer to the question "why are you running 
in this particular election cycle?" Two were removed who, though on the ballot, had no published contact information or website; seven were added who were federal House of Representatives candidates. The resulting population comprised 119 names.

Each prospective respondent was individually emailed approximately one month prior to Election Day from an academic e-mail address. A follow-up group e-mail was sent to all prospective respondents two weeks later.

The survey itself comprised 16 questions. Fifteen were closed-ended questions collecting demographic information (gender, age), political information (party, office sought, number of previous candidacies or elections), and questions regarding recruitment and motivation (intention to run again, intention to recruit others to run). One question was open-ended, asking, "In your own words, what was the single greatest motivation in reaching your decision to run for office in this election cycle (or the most recent in which you were a candidate)?" Finally, the respondent was asked if she would be willing to have the researcher contact her with some follow-up questions. Such a format would allow for longer responses that might shed additional light on the responses.

Those who indicated a willingness to be contacted for follow-up were contacted after the election by the method provided (e-mail or phone), and asked for additional thoughts or details on their "motivation" responses (why will/ won't you run again after your win/loss, why will/won't you be recruiting, any additional details/thoughts on the "why did you run" open-ended response?).

\section{Analysis}

In total, 29 individuals responded to the survey. Of those 29,19 consented to be contacted for follow-up and clarification. The overwhelming majority of respondents were candidates for the Pennsylvania House of Representatives (26/29), which is consistent with the fact that the target population itself was roughly three-quarters candidates for the House. The respondents were predominately Democrats ( $n=23$, slightly overrepresented), with Republicans ( $n$ $=4)$ being underrepresented and Independents $(n=2)$ being overrepresented. Some level of self-selection bias was inevitable, but the characteristics of the group are not especially skewed, with one exception: respondents were overwhelmingly first-time candidates rather than experienced campaigners. Of the 29 , only 1 was an incumbent in the office she was seeking, and 22 of the respondents were in their first campaign. This, however, is a feature rather than a bug given the questions under consideration, many of which seek to examine what (if anything) has changed since November 2016 and whether those changes are lasting or ephemeral. 


\section{Recruitment}

Beginning with the recruitment questions, exactly half of the respondents report being recruited to run for office, half chose to run for themselves, and three did not respond. The question was framed in a generic form ("Were you recruited to run for office?"). "Encouragement" by friends and family was not explicitly considered "recruitment" for the purposes of this study (though in some surveys in the literature the question includes this kind of solicited response), but an open response "Other" option was included in the question asking for the identity or identities of those doing the recruiting, so respondents were able to self-report the encouragement of informal actors/family members as recruitment if inclined to do so.

Respondents were then asked who recruited them and they could select as many as applied between several political and nonpolitical actors (and the aforementioned "Other"). Ten indicated recruitment by one or more political actors (a party official or elected officeholder), while three indicated recruitment by a private citizen or group. The reported rate of recruitment seems low given the power of recruitment as a predictor of candidacy found in the literature, but the wording of the question ("Were you recruited") may have encouraged respondents to think in terms of formal recruitment only, even though it was not explicitly framed as such. The reported positions of those doing the recruiting (by far the most common recruiters were party officials rather than elected officials or private citizens) does seem consistent with the party cartel model discussed earlier, and with the conclusion that respondents themselves were focused on "formal" conceptions of recruitment. At the same time it is possible that self-reporting (as in this survey) is a less-reliable means of measuring recruitment; research in which there is a researcher-defined recruitment as a treatment/independent variable necessarily means that every subsequent "effective" recruitment is captured in the data.

In follow-up interviews, the "unrecruited" did tend to indicate that they were encouraged to run by those within the party. Just more than half of interviewees who had previously stated they were not recruited stated in their interviews that they were at a later point encouraged to run by party leaders. Their negative responses in the initial survey were based on the fact that they had taken it upon themselves initially to attend a political or governmental meeting, and subsequently chose to run, often with a nudge from the party or elected officials with whom they were interacting. Thus, the "procedural cartel" argument still appears to hold water, at least in the sense that the party was still a factor in smoothing the path to candidacy for most of the respondents. The most common comment in the follow-up interviews with regard to 
recruitment was that the party was seen as a tool by all of the candidates-it provided a checklist and a path to beginning one's candidacy. It was not, however, generally trusted or seen as particularly supportive once the campaigns began. As one interviewee put it, "they want you to run because they have a harder time than you'd think getting candidates, but once you're in, they tend to leave you alone. Someone told me, 'don't expect anything from the party, and you'll never be disappointed.' I think that's about right."

Whether rates of recruitment are relatively higher than in past election cycles is not measured by the data, but in any case the purpose of the questions was to demonstrate that female candidate recruitment is both robust (among respondents, most indicate some level of formal or informal recruitment) and can contribute to an explanation for increases in the overall number of women running. Both conditions appear to be met by the data generated in the survey, though naturally this inference should be approached with appropriate skepticism given the sample size and the self-selection of said sample.

\section{Motivation}

The open-ended "motivation" question elicited a fairly narrow set of responses. These were loosely categorized into four groups (presented here alphabetically):

- Democracy: responses that mention systemic concerns such as a lack of electoral competition or partisan tribalism, or system-benefitting virtues like public service or civic duty

- Policy: responses that identify one or more specific policy areas or outcomes

- "Trump": responses that specifically mention the election of Donald Trump as president in 2016

- Values: responses that indicate disagreement, broadly, with the ideology or values of the incumbent officeholder or party

Of these five, democracy was cited most often ( 9 mentions), followed by values (6 mentions) and policy (5 mentions). Two respondents explicitly tied their candidacy to the election of President Trump.

In follow-up interviews, Democrats unanimously mentioned the Republican Party by name as a motivating factor, regardless of whether their concerns were based on policy, values, or democratic values. Interestingly, only half mentioned President Trump, and all but one of those did so in the context that the "problem is bigger than Trump." This was a view shared by those who 
did not mention Trump on their own. When those who had not mentioned Trump were prompted with his name, they shared some variation on this comment, made by one respondent: “The Republicans are Trump now. Who's left that isn't?" The three Republican respondents who answered the question did not share those motivations; all discussed education or a policy related to it (property tax reform, state budget funding formulas).

Observed partisan differences in candidate motivations (even given the extremely small sample size) are consistent with other findings related to candidate recruitment, cited earlier (Norris and Lovenduski 1993; Kunovich and Paxton 2005; Cheng and Tavits 2011). In this case, the arrangement of power in Harrisburg would be a logical explanation for the difference. Republicans control both chambers of the General Assembly, and Democrats would not reasonably expect to be in a majority in the upcoming election. Partisans of the in-power party have more incentive to think of office-seeking in terms of particular policymaking rather than as an act of resistance to broader political trends. It is not inconceivable that intraparty tension within the Republican Party could motivate candidacy, but such a motivation is not in evidence in these survey results.

One item of particular note emerged when comparing motivation across other subsets within the sample: among those who were not recruited, values was the most common motivation cited. In fact, none of those whose responses were sorted into the Values category were also in the "recruited" camp.

\section{Persistence}

Respondents were asked to provide answers on a scale of 1-5 (1 being "Definitely Yes" and 5 being "Definitely No") on three measures of political "persistence," as a way to assess whether their involvement was likely to continue after Election Day. Two questions addressed the likelihood of running for election/reelection to office in the future: one question measured likelihood in the event of victory, the other in the event of a loss. The third question asked whether, regardless of the election outcome, the respondent planned to recruit others to run for office.

In the event of an electoral victory, most indicated they planned to run for reelection or election to another office. The modal average was "probably yes," and 14 (roughly 58\%) selected either "probably yes" or "definitely yes." Only four (17\%) selected "probably not," and none selected "definitely not." The mean numerical average of the responses was 2.46 , indicating a general (though not overwhelming) level of interest in running for reelection. In follow-up interviews, all who won indicated they would run for reelection. 
One, who responded "probably yes" on the survey, said that she did so because she didn't want to "tempt fate" by answering "definitely yes."

Asked to picture an electoral loss, a substantial number $(n=10)$ still indicated they would probably or definitely run again, while five claimed "definitely not." The numerical mean, though, does not shift excessively, landing at 3.04. This indicates only a very slight aversion toward a future run. In followup interviews (post-election), even that slight aversion seemed muted. In the words of one respondent who said she would "definitely not" run again if she lost, "now that the campaign is over, I miss it. I miss seeing the people I was campaigning with [volunteers and other candidates], I miss walking and knocking. Even though I lost, I'm almost positive I'll run again.” This is, it seems, simply harder to contemplate in the midst of a campaign. It's possible that the self-reported drop in likelihood to run again in the event of a loss is a bit like asking a marathoner late in a race whether they'll ever run a second marathon.

The likelihood of future recruitment question suggests that regardless of interest in running in a future election, recruiting is very likely to be part of their political activities moving forward. Two-thirds indicated they would "definitely" recruit and encourage others to run for office, and no respondents selected "probably" or "definitely" not. These responses, taken in light of the findings already present in the literature, suggest that future candidate recruitment in Pennsylvania will include more women as recruiters, and subsequently will potentially yield more female recruits.

\section{Candidacies and Electoral Results}

The Pennsylvania Department of State and the Pennsylvania Center for Women and Politics provide the data needed to compare the recently completed election cycle to the 2016 cycle and the longer historical trends. Given the focus here on effects of the 2016 election and their likely future impact, an explicit comparison of the gender composition of the ballot and results (for the Pennsylvania House and Senate) is indicated.

The 2018 general election ballot saw many more women than the 2016 ballot. Across major and minor parties (and independent candidacies), there was an $80 \%$ increase in the number of female candidates in 2018 (106 candidates) compared to 2016 (59 candidates). It should be noted that although minor party candidates and independents are included in these counts, in neither year did they constitute a large number of the total candidacies.

The results of the 2018 election also demonstrate that female candidates performed well overall. Fifty-two women won their races for the House of 
Representatives, only 34 of whom were incumbents. In absolute terms, this was the single largest increase in the number of women in the House in its history (nine more women are serving in the new House compared to 2016). It is also the second-largest increase in growth year-over-year by percentage, beaten only by 1954 when the number of women jumped from five to eleven (though the paucity of women in the House in 1952 clearly made doubling their number a much simpler statistical feat). In the Senate, 2018 represents both the single largest gain in seats held by women and the biggest gain yearover-year. Both numbers either beat (in the House) or tie (in the Senate) their previous "best" in terms of gender representation, and the General Assembly is now more than $25 \%$ female for the first time in its history (Pennsylvania Center for Women and Politics 2019).

\section{Discussion}

To reiterate, making the case that we are seeing something different that has the potential to generate something like gender equality in representative political institutions in Pennsylvania would likely require one or more of the following to be true: women being recruited for office, an increase in the number of women running for office (whether recruited or not), and some new and persistent motivating factor in the American political ecosystem. The data demonstrate support for at least two of these (and possibly three).

\section{Formal v. Informal Recruitment and Gender}

The respondents to the survey indicated that formal recruitment was certainly not atypical in their cases, but neither was it universal. The followup interviews still suggest that political recruitment was a common feature, even if it did initially involve potential female candidates "presenting themselves at the door" by first becoming more affirmatively politically active before being recruited. "The Party Decides" might be an overstatement, but it is obviously still a prominent feature of the candidacy process. The party appears to be engaging in a form of "convenience recruitment": selecting candidates from those who are more visible on the political activist stage and may be of either gender, rather than from the typical networks of otherwiseprominent and powerful people who, due to patriarchal advantage, are more likely to be men. Ethnographic analysis of the candidate recruitment process (in at least one participant-observer experience) followed a similar path (Weikert 2019), coming after an initial proactive contact of the local party committee. 
There is evidence, too, that the parties currently view female candidates favorably and are more likely to target them for recruitment in the future. One female party official tasked with recruiting candidates for the last two election cycles and interviewed for an earlier study (Weikert 2019) lamented of a prospective candidate, "the only thing that would make him better is if he were a woman." Though anecdotal and party specific, that the sentence was uttered unprompted demonstrates that there is a perception that women, far from having to overcome being a risky choice for the ticket (now-inaccurate conventional "wisdom"), may be electorally advantageous in the modern political climate. Importantly, this is from the perspective of someone doing the recruiting for a major political party.

\section{"A Lot of Women Running"}

Contrary to the prediction of Lawless and Fox, their assessment in The Trump Effect that "on balance, the evidence suggests that very few women will emerge from the overall pool of potential candidates" $(2010,12)$ was understandable but demonstrably incorrect in Pennsylvania. Their contention that high levels of interest would not likely yield a significant increase in female candidacies was consistent with historical cases, but did not bear out in this case. One of the survey respondents said in her interview, "it sure does seem like there are a lot of women running." Indeed, there were. An $80 \%$ increase in the number of female candidacies does more than suggest that more women emerged from the overall pool of potential candidates-it shouts it. A few caveats are perfectly appropriate here, though.

First, this study only examined this phenomenon in one state-Pennsylvania-and while reports broadly noted an increase in the number of women running in 2018, it is entirely possible that other states did not see such a dramatic increase. Second, Lawless and Fox's statement may have suffered from simply misjudging who is counted in the "overall pool of potential candidates." Politically jolted citizens may very well find themselves engaging with the political system. Finding that the barriers to entry for candidacy are not as high as they anticipated, they found themselves in the pool of potential candidates more readily and quickly than our discipline would expect. Last, this phenomenon was not observed broadly, but specifically: the increase in the number of female candidacies can be clearly tied to increases in the number of Democrats and, particularly, Democratic women on the ballot. As Democrats sought to compete in a larger number of races than they had in recent elections, it bears out logically and statistically that the partisan gender gap favoring women as candidates in the Democratic Party resulted in more 
women running in 2018. Thus, Lawless and Fox may have been correct in general, but were made incorrect by virtue of the fact that they did not account for a more wide-ranging electoral competition. Still, whatever the conditions and context, the outright surge of female candidacies (and their subsequent electoral success) cannot be denied.

\section{Motivation and Persistence}

A good circumstantial and qualitative case can be made that the motivation behind the surge of women on the ballot in 2018 is definable and persistent. Where Lawless and Fox may have overstated the case in The Trump Effect is that there was not nearly as much focus on Trump as we would expect. While Trump's election was obviously a startling event for Democrats in general and perhaps Democratic women in particular, that moment of reckoning prompted an evaluation of our political system as a whole-and by the candidates' own reporting in this study it was the Republican Party rather than Donald Trump that animated their candidacies.

We see evidence for this in the "smoking non-recruitment gun." Among the "unrecruited"- those who felt that they came to the system of their own volition rather than being drawn into it by active recruitment by political actors - there was a high incidence of noting a broad dissatisfaction with the governing Republican Party and its values and policy positions. This is important because in 2021 or 2025, President Donald Trump will become former President Donald Trump-but the Republican Party will remain. If Republicanism comes to be considered synonymous with Trumpism, then the departure of Donald Trump from the White House will not necessarily result in a sudden deflation in the motivation of Democratic women to run for political office. If it is these unrecruited women who Lawless and Fox did not expect, and who account for the upswing in the number of women seeking office, then they are likely to continue to do so. This is all the more true if the Democratic Party increases its recruitment efforts among women, and still more true if the Republican Party-seeking to blunt the heuristic effects of female voters who may be more likely to vote for a female candidate-begin recruiting more women to run as well.

The survey and interview results in this study also suggest that the women engaged in the 2018 election cycle are likely to persist. Measures of persistence in this study-limited in sample size though they are-suggest that today's female candidates will be tomorrow's female candidates and that they plan to encourage others to join them. The question explicitly did not ask whether they planned to recruit other women to run, but we can reasonably conclude 
that more women engaging in recruiting efforts will result in a greater degree of female representation. Either they will do so in a gender-blind way (which will naturally tend toward gender equality on the ballot), or they will exhibit the gendered recruiting tendencies discussed earlier, with women being more likely to recruit women and for those recruiting efforts to be more successful than those of men recruiting women (Sanbonmatsu 2006; Cheng and Tavits 2011; Crowder-Meyer 2013). In either case, the important question is not "who will they recruit?" but "will they be recruiting?" The answer appears to be yes. Combined with the advantages of incumbency that will now also attach to the women elected in 2018, it is reasonable to conclude that this year's election is more likely to represent an equilibrium-shifting event than an artifactual aberration.

One final note on persistence. Although not a central feature of this study (and based on an admittedly small sample), the data also suggest a partisan "persistence" gap. The Republican respondents in the survey were far less committed to running in a future election-even in the event of an electoral victory-than the Democrats. None of the four Republican respondents indicated they would "definitely" run again even if they were to win, and sorting the responses by party also changes the "if you lose" persistence measure. Looking only at Democrats, a majority stated they would run again even if they lost in 2018. The implications of such a partisan persistence gap are unclear, but it does seem to buttress the idea that female Democrats (which represent most of the female candidates) view the political context as less of a short-term shock and more of a long-term problem. Such a viewpoint lends weight to the conclusion that recent gains are sustainable as part of a broader trend of increased female participation as candidates for elected office.

\section{Conclusion: Year(s) of the Woman}

The evidence that 1992 represented a watershed political moment and a realigning election year in the wake of the Anita Hill testimony in front of the Senate Judiciary Committee was always thin, even in the context of just that one election year, much less as a signal of changes to come. In comparison, 2018 has the genuine makings of the start of a turned tide, not a temporary wave (though even if just a wave it was still impressive in its magnitude). In 1992, the number of women in the entire General Assembly increased by only 3 , from 25 to 28 . In 2018, that number increased by 12 , from 51 to 63 . The comparatively larger gains in 2018 (both in absolute and percentage terms) show that 2018 far outperformed 1992 even as a "wave" year for women. The survey data collected here suggests that this was not simply a wave, however. 
The three variables noted throughout—recruitment, candidacy, and persistent motivation-all receive support from the data developed and collected. Women in Pennsylvania had both the motive and the opportunity to achieve historic gains in their level of representation in the General Assembly, and they took advantage of both. Nor was this limited solely to the state capitalPennsylvania sent four women to the House of Representatives in Washington as part of what had been an all-male delegation. What remains to be seen is whether these gains will be held and expanded on. The combination of recruitment incentive, active pursuit of candidacy, incumbency advantage, and persistent motivation have the potential to bring women farther along the path to representational equality than Pennsylvanians have ever seen and many might never have expected, but ultimately this study is not about whether this outcome will ever be reached. It is about whether the pace at which that outcome could be reached has experienced a sustainable increase. The data herein suggest that it has.

\section{NOTE}

Acknowledgment: The author wishes to thank the candidates, elected officials, and political and party volunteers who took time during and after a busy election season to provide their invaluable insights and opinions. Any errors in the ensuing analysis are mine alone.

\section{REFERENCES}

Aldrich, John H. 2000. "Southern Parties in the State and Nation." Journal of Politics 62 (August): 643-670.

Bernstein, Robert. 1986. "Why Are There So Few Women in the House?" Western Political Quarterly 39 (March): 155-164.

Carroll, Susan J. 1994. Women as Candidates in American Politics. Bloomington: Indiana University Press.

Caygle, Heather. 2018. "Record-breaking Number of Women Run for Office." Politico, March 8. Available at https://www.politico.com/story/2018/03/08/women-rule -midterms-443267.

Center for American Women in Politics. 2019. Women in Elective Office 2019. Available at: http://www.cawp.rutgers.edu/women-elective-office-2019. Accessed January 13, 2019.

Cheng, Christine, and Margit Tavits. 2011. "Informal Influences in Selecting Female Political Candidates.” Political Research Quarterly 64 (June): 460-471.

Crowder-Meyer, Melody. 2013. "Gendered Recruitment without Trying: How Local Party Recruiters Affect Women's Representation.” Politics \& Gender 9 (4): 390-413.

Delli Carpini, Michael X., and Bruce A. Williams. 1993. "The Year of the Woman? Candidates, Votes and the 1992 Elections." Political Science Quarterly 108 (Spring): 29-36.

Fox, Richard L., and Jennifer L. Lawless. 2010. "If Only They'd Ask: Gender, Recruitment, and Political Ambition." Journal of Politics 72 (April): 310-326.

Freeman, Jo. 2000. A Room at a Time: How Women Entered Party Politics. Lanham, MA: Rowman and Littlefield. 
Kanthak, Kristin, and Jonathan Woon. 2015. "Women Don't Run? Election Aversion and Candidate Entry.” American Journal of Political Science 59 (July): 595-612.

Kazee, Thomas A., and Mary C. Thornberry. 1990. "Where's the Party? Congressional Candidate Recruitment and American Party Organizations." Political Research Quarterly 43 (March): 61-80.

Krouwel, Andre. 2006. "Party Models." In Handbook of Party Politics, eds. Richard S. Katz and William Crotty. London: SAGE. 249-269.

Kunovich, Sheri, and Pamela Paxton. 2005. "Pathways to Power: The Role of Political Parties in Women's National Political Representation." American Journal of Sociology 111 (September): 505-552.

Lawless, Jennifer L., and Richard L. Fox. 2008. "Why Are Women Still Not Running for Political Office?” Issues in Governance Studies, Brookings Institute 16 (May): 1-20.

- 2017. The Trump Effect: Results from a Politico/American University/Loyola Marymount University Survey of Potential Candidates. Washington, DC: Women in Politics Institute.

Norris, Pippa. 1997. Passages to Power: Legislative Recruitment in Advanced Democracies. Cambridge, UK: Cambridge University Press.

- 2006. "Recruitment." In Handbook of Party Politics, eds. Richard S. Katz and William Crotty. London: SAGE. 89-108.

Norris, Pippa, and Joni Lovenduski. 1993. “If Only More Candidates Came Forward': Supply-side Equations of Candidate Selection in Britain.” British Journal of Political Science 23 (July): 373-408.

Pennsylvania Center for Women and Politics. 2019. Fast Facts. Available at https://www .chatham.edu/pcwp/research/fastfacts.cfm\#legislature. Accessed January 13, 2019.

Preece, Jessica Robinson, Olga Bogach Stoddard, and Rachel Fisher. 2016. "Run, Jane, Run! Gendered Responses to Political Party Recruitment." Political Behavior 38 (September): 561-577.

Rallings, Colin, Michael Thrasher, Galina Borisyuk, and Mary Shears. 2010. "Parties, Recruitment and Modernisation: Evidence from Local Election Candidates." Local Government Studies 36 (3): 361-379.

Rubin, Jennifer. 2018. “Republicans Widen the Gender Gap, to Democrats' Benefit.” Washington Post, October 2.

Sanbonmatsu, Kira. 2002. "Political Parties and the Recruitment of Women to State Legislatures." Journal of Politics 64 (August): 791-809.

_. 2006. "The Legislative Party and Candidate Recruitment in the American States." Party Politics 12 (March): 233-256.

Sweet-Cushman, Jennie. 2018. "Where Does the Pipeline Get Leaky? The Progressive Ambition of School Board Members and Personal and Political Network Recruitment." Politics, Groups and Identities, doi: 10.1080/21565503.2018.1541417.

Thomas, Melanee, and Marc Andre Bodet. 2013. "Sacrificial Lambs, Women Candidates, and District Competitiveness in Canada.” Electoral Studies 32 (March): 153-166.

Thomas, Sue. 1994. How Women Legislate. New York: Oxford University Press.

Tolley, Erin. 2011. "Do Women 'Do Better' in Municipal Politics? Electoral Representation across Three Levels of Government." Canadian Journal of Political Science 44 (September): 573-594.

Weikert, Joshua J. 2019. “Inside Two Parties: Ethnographic Analysis of Partisan Differences in Political Candidate Recruitment." SAGE Research Methods Cases. doi:10.4135/9781526473004. 
Williams, Oliver P., and Charles R. Adrian. 1959. "The Insulation of Local Politics under the Nonpartisan Ballot.” American Political Science Review 53 (December): 10521063.

Joshua J. Weikert is assistant professor of politics and chair of the Department of Civic Engagement at Immaculata University, as well as a senior policy advisor to Rep. Joseph Webster, Pennsylvania House of Representatives. His published research focuses on electoral behavior and political communication and he has published several op-eds on political campaigns and elections. Before joining the faculty at Immaculata he served as a visiting assistant professor and adjunct professor at Villanova University, West Chester University, Albright College, and Ursinus College. 